\title{
Social Network Users' Religiosity and the Design of Post Mortem Aspects
}

\author{
${\text { Cristiano } \text { Maciel }^{1, *} \text { and Vinicius Carvalho Pereira }}^{2}$ \\ ${ }^{1}$ Instituto de Computação \\ ${ }^{2}$ Instituto de Linguagens \\ Universidade Federal de Mato Grosso, Av. Fernando Correâ da Costa, n 2367, \\ Bairro Boa Esperança. Cuiabá - Mato Grosso - Brazil - 78060-900 \\ cmaciel@ufmt.br, vinicius.carpe@yahoo.fr
}

\begin{abstract}
Social networks increase the challenges of designing real-world aspects whose computational abstraction is not simple. This includes death and digital legacy, strongly influenced by cultural phenomena, such as religion. Therefore, it is important to analyze youngsters' concepts of death in the web, as the Internet Generation outnumbers other groups of social network users. Besides, due to their age, many of them face other people's death for the first time on the web. This paper analyzes to what extent these users' religion and the belief in afterlife may signal guidelines for a social network project that considers volition towards digital legacy. The data herein analyzed qualitatively and quantitatively come from a survey-based research with Brazilian high school students. The contributions for Human-Computer Interaction (HCI) studies comprise design solutions that may consider aspects of religion, death and digital legacy, also improving users' and designers' understanding on these issues in system design.
\end{abstract}

Keywords: social networks, Internet Generation, post mortem, religion.

\section{Introduction}

In the context of the diverse technological changes we face, especially the large use of social networks, many questions arise and make users and researchers think of their impacts on society. This challenge is bigger for software programs in which users connect, communicate and share content, because there are some real-world facts that migrate to the web and are difficult to undergo computational abstraction. Among these facts, users' post mortem aspects may be hard to design.

Being born, growing up and dying are natural events in human beings' life cycle, but things are not that simple on the web. The misalignment between life and death in the "real" and the digital worlds makes it harder to design post mortem aspects for social networks [13]. Software brings us to a new scenario, in which human beings can become immortal, even if involuntarily.

\footnotetext{
* Corresponding author.
} 
Considering the possibility of immortality on the web, which involves bereavement [3] [17], posthumous interaction [15] and the preservation of users' memory [10], it is also important to discuss the user's volition about the destination of his digital legacy, so as to plan design solutions and provide legal basis for digital wills.

By means of a research with youngsters from the Internet Generation, [15] studied how these users' social representations of death influenced their concepts and practices of posthumous interaction. This research helped to design applications that considered post mortem aspects, by discussing, among other issues: a) which resources in dead people's social network (SN) profiles were most frequently accessed by these youngsters; b) what could be done to their SN accounts after their death, such as blocking some functionalities or password forwarding; and c) whether they would like their accounts to be removed from the SN after death. Other data therein collected are important to the present research, such as the fact that most of those youngsters had got in touch with someone's death for the first time in social networks.

However, other cultural representations, such as religion and funeral rites, are also related to human interactions facing death, which makes it important to study these aspects in a research on digital legacy. As every culture is a sign system, and human practices are systems of signification [9], one must investigate how these phenomena give new meaning to users' ideas about death and legacy. Therefore, we intend to understand in this research to what extent users' religious diversity, different belief systems and opinion about post mortem life can indicate guidelines for a SN project that consider users' volition, i.e. conscious choice, regarding their digital legacy.

In this research, we analyzed data from surveys answered by youngsters from the Internet (or Y) Generation, born between 1977 and 1997[22], who study in a Brazilian state school. The data we collected are interpreted considering previous researches and theoretical background on culture, religion and death. According to data from the Pew Internet research institute [18] on SN users in the United States, Facebook was used by $66 \%$ of Internet users (63\% of the men and $70 \%$ of the women) in 2012 , followed in terms of popularity by LinkedIn (20\%) and Twitter (16\%), although the latter two networks are most used by young adults. On the other hand, $83 \%$ of Facebook users are between 18 and 29 years old. In Brazil, in 2011, data from the Brazilian Internet Steering Committee (Comitê Gestor da Internet no Brasil - CGI) [6] also revealed that in $201183 \%$ of young people aged 16 - 24 use social networking sites, such as Orkut, Facebook and LinkedIn.

For the HCI field, we contribute in terms of design solutions that may consider religion, death and digital legacy, so as to deepen users' and designers' understanding on the role of death in system projects. From an epistemological point of view, bringing religion as a cultural aspect to HCI discussions is an attempt to study, from a computational perspective, another lens through which humans see reality and their interactive processes. In this research, religious diversity is regarded as an analysis variable, although science and religion are traditionally considered opposite areas. Thus, we have adopted Einstein's investigative paradigm: "science without religion is lame; religion without science is blind". 
This paper is structured as follows: after this introduction, we present some theoretical background on the main issues discussed herein (section 3). Then, the research methodology is described. In section 4, the case study is presented and discussed. Finally, the conclusions and references are enlisted.

\section{Theoretical Background}

In order to analyze post mortem digital legacy, besides identifying the state of the art in this area, it is necessary to study culture, religion and death in our society.

\subsection{Culture, Religion and Death}

Religion is an inextricable part of life in society. [8], one of the first sociologists who studied religion scientifically, ascribes to religious practices the first human representation and symbolization systems, which determine abstract notions of time, space and causality. According to this sociologist, religion is a social fact, which makes it a common phenomenon to all human communities.

This idea of religion as a human practice emerging from social interaction is closely related to Geertz's view [9]: religion as a cultural system. In this context, the concept of system also applies to Anthropological Semiotics, which understands every culture as a sign system, and human practices as systems of signification.

The same definition of culture is employed by researchers on Semiotic Engineering, in the HCI field [20], to discuss projects and design solutions that consider cross-cultural aspects in computer-mediated communication, either between users or among users and designers. Therefore, among many definitions of religion (profane and sacred ones), this research spouses Geertz's view, as it is widely spread in HCI discussions and may bring some light to system projects facing digital legacy and cross-cultural religious diversity.

The connection between religion and death goes far beyond the comfort that sacred matter can bring to bereavers: religious funereal rites found culture [19], no matter if they are festive or mournful. This means that men abandon their state of nature and humanize in contact with someone's death, by waking, celebrating or mourning the corpse, i.e. ascribing meaning to a body that ran out of biological function. Then, the corpse has become a pure support for symbols, interface where men place values, feelings and material objects. Regarding these farewell rituals, we can see how human beings try to keep in connection to the dear ones that are no longer alive, driven by their imaginary and using symbols such as candles and flowers.

Actually, "death is a natural and non-classist fact. But it is also a social and cultural fact. As a social fact, it is stratified; as a cultural fact, it is intertwined with values and meanings" [21]. This set of cultural meanings, organized into religious systems, works as guidelines for people in their interactive practices with the dead: oblations, prayers, bereavement or bequeathment. People's beliefs determine who can interact with the dead, when, why and how to do it. [21] reinforces this idea by stating that "death entails the development of exclusion mechanisms, and their frontiers in 
different cultures are established by the limits between the sacred (the world of the dead) and the profane (the world of the alive). This duality lies underneath the collective imaginary and creates an invisible world parallel to the events of life.

In the Brazilian context, the three religions with greater amounts of believers are Catholicism $(64,62 \%$ of the population), Protestantism $(22,16 \%)$ and Spiritualism $(2,01 \%)$, according to the data from the 2010 census [11], which quantified also the number of people with no religion $(7.6 \%)$ and atheists $(0,3 \%)$. In this discussion, it is not up to us to question God's existence or post mortem life; instead, we focus on the fact that religion, as an element of culture, has its own meanings, possibly influencing the use and design of social software.

Based on these pieces of information and on the fact that most participants in this research are either Catholics or Protestants, it is necessary to understand how these religions deal with death. As they are both Christian religions, with a common historical background, Catholicism and Protestantism bare resemblance to each other when it comes to the understanding of death as a passage to an eternal life, denying reincarnation. However, whereas Protestants only believe in Heaven or Hell as afterlife destinies, Catholics consider also a third option: Purgatory. In terms of ritualism, the ceremonies of wake and burial in these religions are similar, although many Protestant groups do not employ candles as Catholics. Furthermore, whereas Catholics pray for the soul of the dead, Protestants tend to pray for those who are alive[7]. After the burial or cremation, it is common for Catholics to celebrate requiem masses seven days, one month and one year after the day of the death; on the other hand, such rituals do not exist in Protestantism[7]. This difference is related to the existence of a specific ritual for death among Catholics: extreme unction.

Some research has been done on religion and technology in the area of HCI. According to [25], although the design-oriented research examining religion is growing, only a handful of the world's major faiths have been studied. The uses of technologies in religious practices are also studied by [26], who presented results about the uses of technologies in three aspects of religious work: religious study and reflection, church services, and pastoral care. In another study, more focused on HCI, [24] analyzed how topics of interest to HCI researchers (e.g., material artifacts, routines, and Information and Communication Technologies use) are used for religious purposes. In their related works section, these authors presented an overview of researches on similar issues, grouped into three major categories: religion online, design explorations, and studies of appropriation. The aforementioned studies present interesting contributions about the relation between technology and religion, but do not specifically address this topic from the perspective of death and its taboos.

\subsection{Related Works}

In the HCI field, researches on this subject are recent and study the relation among death, mortality, bereavement and technologies. Particularly [16] have been doing research on HCI and the end of life in a lifespan-oriented approach. Other researchers, such as [3], investigate users' behavior in social networks, based on their posts to dead people. In Brazil, researches have been done on post mortem data management. 
In this sense, according to [13], social software must comprise a volition element, that is, software planning must consider the user's decision on the destination of his digital legacy. In his research, the author presented some possibilities that were considered in planning design solutions for posthumous digital legacy, such as:

1. attributing password power to third parties, while alive or in a will, attesting the wish for posthumous interaction. It is important to notice that password forwarding is a service that some specialized enterprises offer, studied by researchers like [4].

2. having a back-up copy of the digital legacy in some equipment or in a network, so that login and password are not necessary for access. Although this is an option to preserve digital legacy, this would be too demanding for users, because of the need for constant backup and software restrictions.

3. keeping a link with real-world institutions and documents to confirm one's death, in the context of the social web. However, many changes would have to occur so that these processes were aligned, which would affect both governmental institutions and the laws of the jurisdiction where users live or the applications are hosted.

4. providing resources in the very social web applications to register users' volition. In this case, the user could choose via software the destination of his digital legacy. This would have a strong impact on the terms of use developed by software enterprises and agreed with by users.

Such solutions came out of a research with 83 software engineers [13]. That research also resulted in a list of requirements for social web applications that could provide users with volition functionalities for post mortem digital legacy (as in option $\mathrm{d}$, from the aforementioned solutions).

In an extension of that research, [14] discussed how taboos and beliefs on death are an integral part of life in society and may affect, for instance, system development. To understand this phenomenon, software engineers' discourse was analyzed considering taboos and beliefs over death, which could condition the proposal of solutions to model digital legacy aspects for social networks. Seven categories of beliefs were generated and discussed, according to the software engineers' opinions: non profanable legacy, funeral rites, the immaterial beyond death, death as an end, death as adversity, death as interdiction, and the space required by death. In terms of results, that research found a predominance of the concepts of something immaterial beyond death and that death is an end in itself, two antagonist trends that might influence software development concerning death issues.

With regard to managing dead users' digital legacy, [27] defined four possible destinations for such data in social networks: leaving (not doing anything to the account), deleting (removing the account), forwarding (giving the password or part of the assets to an heir) or archiving (keeping a backup copy of the data, maybe in material medium). Regarding the choice to leave passwords for an heir, [12] have not identified clauses about password transfer in case of death in the terms of use of Facebook, Google+ and LinkedIn, in three different countries (USA, UK and Canada). Finally, there are data that become unmanageable after the death of the account owner, as there are no means to access them. 
The data of people who die, available on the web, permit posthumous interaction, that is, the system interaction with deceased people's data, or between users and deceased people via system [15]. These authors reinforce that it is worth stressing that the datum itself is not posthumous, as it was produced by the user when alive. Posthumous is the interaction occurring with data belonging to someone already dead, a process which is guaranteed by the asynchronous character permeating a large share of the communicative processes in the Internet. In that research, conducted with youngsters from the Internet Generation, it was discussed how the death representations of such generation influence their conceptions and practices on posthumous interaction.

There is evidence, however, that this posthumous interaction falls in frequency over time. [3] observed from empirical analyses on deceased users' profiles on MySpace that comments on these pages reached a peak on the day of the death, decreased quickly within 10 days following this event and then reduced more slowly. The analysis of posthumous interaction is most often accomplished through empirical observations on websites than in interviews with the bereaved, given the emotional charge involving the death experience. The same applies to the study of real-world mourning practices, as it is more common to observe externally a funeral rite than to interview its participants [23].

Regarding the importance of semiotics in the design of systems that consider post mortem issues, it is necessary to discuss symbols or images related to this context. Proposing some useful guidelines for the development of systems that consider the possibility of digital mourning, [16] mentioned the importance of permitting the bereaved to control and choose their death-related symbols, determined in part by their belief systems, taboos and religious diversity. These authors also warn that some mourning symbols are extremely private, while others are meant to be publicly viewed.

However, are the users' wishes on the fate of their digital legacy influenced by religious beliefs? This issue is discussed by means of a case study in Section 3.

\section{$3 \quad$ Methodology}

This research was conducted with teenagers taking integrated secondary and technical education at a public school in Cuiabá (Mato Grosso - Brasil), called Instituto Federal de Mato Grosso. The school has 442 students in this segment, 78 of which participated in the research. Because of their age, these users are part of the Internet Generation, born between 1977 and 1997, according to Tapscott [22].

Initially, during the period from June 1 st to 12 th, in 2012, one of the researchers went to these students' classrooms, to provide them with a brief explanation about the research and give them a Term of Consent for answering the questionnaire, according to Brazilian Legal Resolution 196/96 [2], which establishes regulating directives and norms for researches involving human beings. As they were underage, the Terms of Consent had to be signed by their parents or person in charge, so that, at a set date, these young people responded to the questionnaire. However, this procedure was harmed because many students failed to bring the Term signed, saying they had either 
forgotten to bring it, or failed to show it to their parents. Hence, it was not possible to assess how many had not been granted permission to participate in the research and how many failed even to tell their parents about it. Maybe the very application of the questionnaire was affected by taboos concerning death or religious issues, hindering a more systematic reflection on the theme.

220 Terms of Consent were delivered and 78 students brought them signed. They participated in the research, filling in an individual anonymous questionnaire in the classroom. Considering all users who have expressed interest in participating in the survey, we have an intentional non-probability sample, composed of a known and finite population, which admits a maximum error of $4.7 \%$, and desired confidence level of $95 \%$.

The questionnaire had 33 questions, open and closed ones, divided into general data, knowledge on computing and on the internet, religion, social networks and posthumous data, and representations of death. To create the questionnaire, issues raised in previous researches and theoretical background in the area were taken into account, including a research instrumented with a 404-question questionnaire [1], the social representations of death categorized by [5], issues raised by software engineers as to the possibility of volition concerning the digital legacy [13], and these professionals' taboos and beliefs about death [14]. The planning of the data collection instrument was crucial to the research. It should be stressed that, before applying the questionnaires to the teenagers, a pilot research was conducted with the planned instrument. 19 students of a MSc program participated in it, who study education technologies and generational differences. The pilot questionnaire allowed significant adjustments to the instrument, especially in order to clarify some questions.

Initial data from this research were analyzed by [15]. In that first analysis, the authors investigated how the Internet Generation's social representations of death influenced their conceptions and practices of posthumous interaction in social networks. 15 questions were analyzed then, and 5 correlations were made among the questions, via software. Now, in the present research, the questions about religion were analyzed and correlated with those on users' volition about the destination of their post mortem digital legacy. To do so, the data were fed into an Excel spreadsheet and tabulated in SPSS (Statistical Package for the Social Sciences), for later quantitative-qualitative data analysis. The questionnaire questions were identified by the letter "P" for data analysis. From the total set of questions in the instrument, 18 were analyzed in this research, and 8 correlations were made among them, via software. That selection considered the focus of our proposal. In the qualitative analysis of the only open question, the teenagers were identified by the letter " $\mathrm{J}$ ", followed by the questionnaire numbering. In the next section, these data are analyzed.

\section{Data Analysis}

In this section, the data tabulated are analyzed and discussed. 


\subsection{Demographic Data}

Our research included $17.65 \%$ of the secondary education students of a federal school in Cuiabá (Mato Grosso - Brazil). All the teenagers belong to the "Internet Generation": $2.6 \%$ of them were born in $1993 ; 2.6 \%$ in $1994 ; 28.2$ in $1995 ; 39.7 \%$ in $1996 ; 24.4 \%$ in 1997 ; and $2.6 \%$ in 1998 .

Out of the teenagers participating in the research, $69.2 \%$ were female and $30.8 \%$ male. $93.6 \%$ answered they had a computer at home and $6.4 \%$ said they did not. About $73 \%$ of the teenagers declared to use the Internet for 1-4 hours a day. Among the most frequently accessed sites, $79 \%$ mentioned the SN Facebook, followed by Google (37.1\%) and by Hotmail (25.6\%), considering that each answer could contain up to three sites. Hotmail is observed to have the MSN communicator integrated to the system, which also constitutes a SN. 62 out of the 78 participants have Facebook accounts.

These sample data allow us to state that the great majority of the participant teenagers frequently use computers and the Internet frequently, making constant use of social networks. Thus, it can be considered that this research is really based on the opinion of the "Internet Generation".

\subsection{Religion}

The questionnaire had 5 specific questions that focused on religious issues and funeral rites. In question P8, 94.9\% of the participants answered that they believed in God, whereas 3.8\% do not share such belief and $1.3 \%$ did not answer the question. When asked about which religion they belong to, most students said that they are either Catholics or Protestants, among some other religions, as we can see in Table 1.

Table 1. Users' religion

\begin{tabular}{lc}
\hline \multicolumn{1}{c}{ Religion } & \% \\
\hline Catholics & 33,3 \\
Protestants & 48,7 \\
Spiritualists & 5,1 \\
Jeovah's witnesses & 1,3 \\
No religion & 10,3 \\
No answer & 1,3 \\
\hline
\end{tabular}

Conversely to the Brazilian 2010 Census [11], this group of youngsters has more Protestants than Catholics, besides some Spiritualists and a single Jeovah's Witness. Perhaps, this disparity is due to other demographic aspects, such as social classes, parental educational level, location of the school etc., which were not investigated in this research. Among the participants, there were no Jews, Buddhists or Muslims.

Question P10 asked if these youngsters engaged in religious rites. 38,5\% answered "Yes, always"; 42,3\%, "Yes, sometimes"; 7,7\%, "No, never"; and 11,5\% did not answer this question. Crossing the data from questions P10 and P9, the results suggest that most youngsters are not constant practitioners of their religions, as table 2 shows. 
Table 2. Religion x Religious practices

\begin{tabular}{lccc}
\hline Answer & Catholics (\%) & Protestants (\%) & Spiritualists (\%) \\
\hline Yes, always & 34,6 & 48,6 & 50 \\
Yes, sometimes & 53,8 & 43,2 & 50 \\
No, never & 11,5 & 8,1 & - \\
\hline
\end{tabular}

Such data suggest that those who are not constant practitioners of their religions might not be strongly influenced by their rites and dogmas concerning death and legacy. This is in close relation to the fact that religious systems are not homogenous, so that Catholic practices may differ from parish to parish, as well as Protestant attitudes vary from pastor to pastor.

In question P11, when they had to answer about post mortem life, $61,5 \%$ of the respondents stated that they believed on it, whereas $38,5 \%$ said they don't. This question, different from the others, was not left blank by any participant, which suggests some kind of conviction on this topic. However, it is interesting to notice that post mortem life is a dogma that Catholics, Protestants and Spiritualists spouse, although their understanding on this issue is different. The fact that a significant amount of youngsters said that they do not believe in post mortem life confirms the aforementioned interpretation that their beliefs do not necessarily match the dogmas of their religions.

The 48 participants who answered that they believed in afterlife were asked another question (P12) on the meaning of life after death. They were given three answer options: "the migration of the soul to another physical body", chosen by 3 respondents; "life in parallel worlds", chosen by 29 respondents; and "other", chosen by 16 respondents.

Those who answered "other" were asked to explain, with their own words, the meaning of "afterlife". Analyzing the answers, it is very clear that the meaning of afterlife for these youngsters lies on where this life takes place, rather than what it consists of. Locative expressions, such as "in Heaven" or "beside God" are repeatedly present in their answers, as for instance: "It means to go either to Heaven or Hell, according to how you lived on Earth" (J12), and "Living close to God after His return" (J56). We also emphasize the predominance of typically Christian images in their explanations on afterlife, such as "Heaven", "Hell", "Jesus Christ" and the "Last Judgment", confirming the religious profile identified in P9. Here are some of the responses containing these images: "Eternal life with God and His son Jesus Christ" (J32), and "When we die, we will wait for the final judgment" (J71).

If we compare the results of P11 (belief in afterlife) and P9 (users' religion), the results show that $76,9 \%$ of the Catholic respondents believe in post mortem life, $47,4 \%$ of the Protestants, $100 \%$ of the Spiritualists and $62,5 \%$ of those with no religion. The distinction between the answers of Catholics and Protestants confirms, once more, that these youngsters' beliefs do not necessarily match the dogmas of their doctrines, as afterlife is a common element for Catholicism and Protestantism, even if slightly different in certain theological aspects. 


\subsection{Procedures after the User's Death}

In question P30, the participants should choose up to three alternatives indicating what they wanted to be done to their SN accounts after death. It is important to recall here that, as explained in the methodology section, such alternatives consisted of procedures selected from previous researches on the subject [13] [14], conducted with software developers.

Table 3 shows the correlation between the answers to P30 and users' religions (P9). As respondents could choose more than one option in P30, 204 answers were deemed valid. The acronym NR means the amount of choices for each option.

Table 3. Procedures after the user's death vs users' religion

\begin{tabular}{|c|c|c|c|c|c|}
\hline Procedure after the user's death $(\mathrm{nr}=204)$ & $\begin{array}{l}\text { Catho } \\
\text { lics }\end{array}$ & $\begin{array}{l}\text { Protes } \\
\text { tants }\end{array}$ & $\begin{array}{l}\text { Spiritua } \\
\text { lists }\end{array}$ & $\begin{array}{l}\text { No } \\
\text { religion }\end{array}$ & $\%$ \\
\hline $\begin{array}{l}\text { a1) A farewell message written by you should be } \\
\text { shown on your profile, as soon as your death is } \\
\text { confirmed (nr=42) }\end{array}$ & 61,5 & 55,3 & 50 & 37,5 & 53,8 \\
\hline $\begin{array}{l}\text { b1) A user previously selected by you should be } \\
\text { given your login and password. However, he would } \\
\text { have to obey the commands you left in a digital will } \\
(\mathrm{nr}=37)\end{array}$ & 42,3 & 52,6 & 25 & 62,5 & 47,4 \\
\hline $\begin{array}{l}\text { b2) An heir previously selected by you should be } \\
\text { given your login and password, but free to do } \\
\text { whatever he wanted to your account and data (nr=7) }\end{array}$ & 15,4 & 2,6 & 0 & 12,5 & 9 \\
\hline $\begin{array}{l}\text { c1) Your account should be immediately deleted, in } \\
\text { case of official report of your death }(\mathrm{nr}=17)\end{array}$ & 30,8 & 18,4 & 0 & 12,5 & 21,8 \\
\hline $\begin{array}{l}\text { c2) Your account should be deleted by the end of a } \\
\text { pre-selected period after the official report of your } \\
\text { death. Within this period, your contacts would be } \\
\text { normally able to access your account ( } \mathrm{nr}=21 \text { ) }\end{array}$ & 15,4 & 34,2 & 50 & 12,5 & 26,9 \\
\hline $\begin{array}{l}\text { d1) Your account should remain active on the } \mathrm{SN} \text {, } \\
\text { so that any user could see it }(\mathrm{nr}=14)\end{array}$ & 11,5 & 18,4 & 0 & 37,5 & 17,9 \\
\hline $\begin{array}{l}\text { d2) Your account should remain active on the } \mathrm{SN} \text {, } \\
\text { but only your friends would be able to see it }(\mathrm{nr}=17)\end{array}$ & 26,9 & 18,4 & 25 & 12,5 & 21,8 \\
\hline $\begin{array}{l}\text { d3) Your account should remain active on the SN, } \\
\text { but only some previously selected friends would be } \\
\text { able to see it (nr=5) }\end{array}$ & 7,7 & 2,6 & 25 & 12,5 & 6,4 \\
\hline $\begin{array}{l}\text { e1) Your data should be sent to a virtual cemetery or } \\
\text { a memorial profile, containing only some } \\
\text { information you chose, such as date of birth and } \\
\text { date of death ( } \mathrm{nr}=24)\end{array}$ & 26,9 & 34,2 & 25 & 25 & 30,8 \\
\hline $\begin{array}{l}\text { e2) A backup copy of your data in the SN should be } \\
\text { sent to an heir chosen by you }(\mathrm{nr}=20)\end{array}$ & 26,9 & 15,8 & 50 & 50 & 25,6 \\
\hline
\end{tabular}

For a better analysis of these data, five categories were created, as described below. 


\section{a) Recording a posthumous message (item al)}

It is noticed that one of the most frequent options, chosen by 42 participants, expresses the desire to leave a posthumous message, displayed after the detection of the user's death. This option was the most frequently chosen, regardless of the user's religion, although it was more widespread among Catholics (61.5\%). Then, communicating something can be seen as a last wish for most of these users, which confirms the use of social networks primarily for communication among people, even in the context of death. This seems to apply irrespective of religion, according to our sample.

Besides, confirming what [23] presented, the desire to leave a posthumous message shows that death on Social Networks is not a taboo issue that one should hide. This idea of death as an interdicted subject was also found by [14] as an infrequent concern in software developers' solutions for digital legacy projects, which seems to match users' answers in this research.

\section{b) Naming an executor for your digital will (items b1 and b2)}

Another frequent option, chosen by 37 participants, entails naming an executor for a digital will, by forwarding the user's password and login to someone else (b1). This was the second most frequent option among representatives of all religions, except Spiritualists. Those who stated to have no religion were the most inclined to such procedure $(62.5 \%)$. However, such solution requires a further discussion on legal issues related to digital assets.

On the other hand, only 7 participants chose the option b2, which implied further concerns on caution and privacy of the data. This option was seldom chosen, regardless of the user's religion. Forwarding passwords is an alternative discussed by [4], but such action must not be disassociated from a will, as this could cause a series of problems analyzed by [13], just like misappropriation of identity, for example.

Making a will is also somehow related to the locative concern of afterlife respondents showed in question P12. Defining where (or whom) the data go to may provide some certainty in an area where doubts are predominant. Besides, the writing of a will is a very common practice in real world, so that the Internet Generation users expect this phenomenon to be modeled for computational purposes too.

\section{c) Deleting the social network account (items c1 and c2)}

38 participants chose options that involved account deletion from social networks, either immediately after death (c1) or after a previously set period (c2). The immediate exclusion was mostly chosen by Catholics (30.8\%), whereas Protestants $(34.2 \%)$ and Spiritualists $(50 \%)$ opted for deletion by the end of a predefined time span. Such variation might be due to the differences between the funeral rites of these religions. The fact that Catholics keep celebrating requiem messes after death, besides other more intimate rites, might lead them to feel more comfortable with an immediate exclusion of the account, as they are more familiar to rites that do not involve the presence of the deceased person. 


\section{d) Keeping the account active (items $d 1, d 2$ and $d 3$ )}

Conversely, 36 participants indicated that their accounts should be kept active on the SN. Those who claimed no religion were the ones who most frequently chose the option d1, in which the account would remain active and could be viewed by any user. This shows an indirect desire to remain interacting with the alive, even if posthumously, possibly because the lack of religion reduced incidental taboos that might prevent this kind of interaction. When presenting some design solutions that support similar users" decisions, [16] affirm that "we can consider how systems might empower people who have died to maintain a digital identity that preserves their integrity and desires in this life; or, to deliver messages for loved ones into the future."

Among the three options in this category, d2 was the most frequently chosen, especially among Catholics (26.9\% of these users) and Spiritualists (25\%). Option d3, which demanded a more specific selection of users who would be allowed to see the dead user's profile, was infrequent among the participants, regardless of religion, except for Spiritualists (25\% of them). The unpopularity of this option might be due to the public nature of death in cyberspace, especially in social networks [23], so that users do not feel uncomfortable to share with their online friends the fact of death.

\section{e) Preserving the digital legacy (items e1 and e2)}

Another category of options indicated by the participants concerns data memory. 24 participants manifested the desire to have their data sent to a Virtual Cemetery or a profile memorial after death (e1), whereas 20 demanded that a backup copy of their data on the SN was sent to a previously selected heir (e2).

It was noticed that the preservation of the digital heritage is something desired by most respondents, regardless of religion: item e1 was the third most chosen option, selected by $30.8 \%$ of the participants. Item e 2 was also chosen by $50 \%$ of the Spiritualists, and $50 \%$ of those who claimed no religion.

This data preservation is connected to the aforementioned locative concern about afterlife, as keeping the legacy entails the decision on where to keep it. Defining a place to store such data goes hand in hand with the religious concerns on where the soul is deemed to go after death, and with the legal concern about whom to give the legacy to. Therefore, most respondents preferred options in which the legacy was transferred to specific environments for this kind of data (as cemeteries and memorials), instead of keeping them like other data in the SN (as in items d1, d2 and d3).

The answers to question P30 were also correlated with those to P11, so as to investigate whether the belief in afterlife could influence users' choices of procedures. However, this correlation did not present a significant difference between the choices of those who believed or not in post mortem life, especially when comparing Protestants and Catholics. Possibly, such similarities are due to the resembling interests and basilar doctrines of these Christian religions.

In question P22, users had to answer if they would like to set their SN accounts and determine their preferences about what should be done with their profile after death, as if making a will for digital assets. $67.9 \%$ of the participants answered "yes"; $29.5 \%$, "no"; and $2.6 \%$ did not answer. Analyzing such data, it is clear that these young 
people intend to customize the destiny of their legacy, which confirms the customization characteristic [22] identifies with the Internet Generation. This is another option for social networks, which might prove useful in cases when the profile must be managed by an heir (as discussed in the items d1, d2 and d3, from P30).

Those who answered "yes" to question P22 were asked in question P23 to select from a list which resources they would like to block in their SN accounts after death. Notice that they could select as many options as they wanted. The data from P23 were correlated with those from P11, in order to analyze if the belief in afterlife could influence users' choices on which resources to block. In general, we could see that those who believed in post mortem life opted to block more resources. Possibly, the idea of remaining somehow alive after death conflicted with the idea of not being able to manage their own account, so that these users opted for blocking most resources.

On the other hand, the two options of blocking most frequently chosen (blocking chats and blocking external applications) were slightly more popular among those who do not believe in afterlife. It is interesting that both functionalities would require some sort of response from the deceased user (even if in afterlife), so that those who do not believe in post mortem life tend not to consider relevant to keep these functionalities working. It is also noteworthy that the difference between the proportions of afterlife believers and non-believers was greater for the following options: blocking old messages visualization, blocking old notes liking, blocking content sharing and blocking access to the profile information. Table 4 presents these data in detail.

Table 4. Belief in afterlife vs. functionalities blocking

\begin{tabular}{llcc}
\hline \multicolumn{1}{c}{ Blocking resources in case of death } & \multicolumn{2}{c}{ Belief in afterlife? (\%) } \\
& & Yes & No \\
\hline 1. blocking chats & 66,7 & 71,4 \\
2. blocking external applications & 39,4 & 42,9 \\
3. blocking old messages visualization & 39,4 & 19 \\
4. blocking history updating & 33,3 & 23,8 \\
5. blocking note posting & 30,3 & 23,8 \\
6. blocking comments about photographs & 27,3 & 23,8 \\
7. blocking comments about old notes & 27,3 & 23,8 \\
8. blocking old notes liking & 27,3 & 9,5 \\
9. blocking content sharing & 24,2 & 9,5 \\
10. blocking access to the profile information & 21,2 & 0 \\
11. blocking access to photographs & 12,1 & 9,5 \\
12. blocking no resource & 12,1 & 4,8 \\
\hline
\end{tabular}

However, new data arise when we correlate the choices on functionalities blocking (P23) with users' religion (P9). Below, one can see Table 5, whose columns are numbered according to the caption of Table 4 : 
Table 5. Religion vs. functionalities blocking (\%)

\begin{tabular}{lllllllllllll}
\hline Religion & 1 & 2 & 3 & 4 & 5 & 6 & 7 & 8 & 9 & 10 & 11 & 12 \\
\hline Catholics & 76,5 & 41,2 & 23,5 & 35,3 & 29,4 & 35,3 & 29,4 & 23,5 & 35,3 & 11,8 & 11,8 & 5,9 \\
Protestants & 73,1 & 46,2 & 42,3 & 30,8 & 30,8 & 26,9 & 30,8 & 23,1 & 15,4 & 15,4 & 11,5 & 3,8 \\
Spiritualists & 50 & 50 & -- & -- & 50 & 25 & 25 & 25 & -- & 25 & 25 & 25 \\
No religion & 40 & 20 & 40 & 40 & -- & -- & -- & -- & -- & -- & -- & 20 \\
Global average & 68,5 & 40,7 & 31,5 & 29,6 & 27,8 & 25,9 & 25,9 & 20,4 & 18,5 & 13 & 11,1 & 9,3 \\
\hline
\end{tabular}

By analyzing these data, we can see some common interests of Catholics and Protestants regarding which functionalities to block, possibly due to the similarities between these religions. There are only significant differences considering the options "blocking old messages visualization", mostly preferred by Protestants, and "blocking content sharing", mostly preferred by Catholics. Spiritualists also chose fewer resources to be blocked. Those who have no religion have chosen to block only 4 items, which suggests that the lack of religiosity might lead to fewer taboos regarding death, and therefore less fear from legacy profanation.

\subsection{Symbols}

When the choice on symbols to depict death (P32) is correlated with the users' religion (P9), there are some subtle differences between the signs chosen by each religious group, as shown in Table 6.

Table 6. Symbols vs religions

\begin{tabular}{lcccc}
\hline Symbol & Catholics $(\%)$ & Protestants (\%) & Spiritualists (\%) & No religion (\%) \\
\hline Cross & 23,1 & 18,4 & 25 & 25 \\
Tomb & 19,2 & 10,5 & & \\
Gravestone & 11,5 & 10,5 & & \\
Skull & 3,8 & 7,9 & & 25 \\
Light & 7,7 & 10,5 & 25 & 25 \\
Coffin & 15,4 & 23,7 & & \\
Sky & 15,4 & 10,5 & & \\
Others & 3,9 & 8 & 50 & \\
\hline
\end{tabular}

The analysis of such data shows that the cross is a common symbol for these users' religions, representing Christ's death and therefore common people's death as well. On the other hand, there is an important difference regarding the second most frequent choice on these symbols: whereas Catholics tended to prefer the tomb, Protestants felt more inclined to choose the coffin. This might be a result from the fact that Protestants tend not to visit cemeteries as frequently as Catholics [7].

Spiritualists opted for less morbid symbols, such as the cross and the light, which might reflect their view on death and life as cyclical phenomena, instead of sad mishaps. The sky was not among their choices, maybe because it is too closely 
associated with Heaven, in opposition to Hell, and this dichotomy is traditionally not part of Spiritualist beliefs. Also regarding morbidity, the skull was the most infrequent choice in this question, suggesting that users do not want to face physical decay or destruction as a symbol on their social networks.

Although the sample consisted of too few Spiritualists, we cannot neglect that half of them opted for the alternative "others", a hint that the symbols proposed in the questionnaire were maybe too intertwined with Christianity and did not represent other religions. One of these users proposed the symbol of God moving toward the deceased, and the other chose the symbol of Ouroboros, a pagan myth of a serpent that devours its own tail.

Correlating question P32 with P11 (on users' belief in afterlife), the results showed that those who believed in post mortem life tended to choose the light $(18,8 \%$ of the believers) and the cross $(16,7 \%)$. On the other hand, those who do not believe in afterlife tended to choose the coffin (26,7\% of the non-believers) and the cross $(20 \%)$. As it was said before, the cross is a dominant symbol in the answers due to its importance in Christianity, no matter if users believe or not in post mortem life. The choice on the coffin by those who do not believe in afterlife and consider death as an end in itself can be related to the material sense this symbol brings to death, instead of a more transcendental one possibly related to afterlife and the symbolism of light.

\section{Conclusions}

Religion, along with gender and ethnicity, is part of the diverse ways of understanding the world and individuals. Thus it is paramount to do research on elements from these fields that may contribute to the design of more universal applications which respect cultural diversity and meet the needs of digital life, until its very end.

However, many people are not comfortable with the idea of death, due either to fear of the unknown or to bonds of affection and friendship established by life in society and strongly influenced by culture. From the computational viewpoint, the treatment that is given to modeling users' post mortem aspects requires further studies.

Regarding religion, there is an inextricable diversity that must be considered in cultural research. In the research presented herein, only the most popular religions in Brazil [11] are represented. However, there are different religious profiles in different countries, which have a strong influence on the design of computational systems, and sometimes on political and legal systems that may influence software use. Thus, there is a great challenge to the analysis on how these different expressions of culture can influence applications design.

As for the procedures to be done with the users' accounts after their death, we realize that most respondents in this research chose options that imply moving the data to another location, such as sending data to a digital cemetery, or handing them to an heir. This choice is closely related to religiosity, since these users also defined afterlife by means of a locative change. By this choice, they expressed a desire to 
change either the way the data are displayed in the SN or the person in charge for managing them, in the case of a digital will.

Regardless of the options chosen by the users in this study, one notices that there are different desires concerning the fate of the digital legacy, which indicates that systems should not only provide functionalities to handle these assets, but also give users flexibility to configure their accounts according to their volition. Of course, these features must be designed according to the laws of each country, but one must not forget that laws are created to meet the demands of society. At this point, this research shows some possibilities to discuss and develop new norms and laws concerning digital legacy.

The discussion on symbols representing death may suggest some guidelines for icons that can be used along with functionalities in applications that deal with post mortem digital legacy, in order to permit the expression of different understandings of death in graphical interfaces.

One of the limitations of this research is its representativity for the whole Internet Generation. According to Tapscott [22], this generation comprises those who were born between 1977 and 1997. As this research addresses interviewees who were born between 1993 and 1998, this study represents only part of the Internet Generation time span.

For future works, it is necessary to have a larger and more representative sample of different religions, also considering users from other generations. Nevertheless, the method herein employed and the objectives of this research make clear that this study is significant for the design of more universal solutions. Considering religion as a lens to see the world and the interactive processes among people is a possibility that should not be ignored by designers and the HCI community.

\section{References}

1. Boukharaeva, L.M.: Os valores educacionais dos estudantes nos limites da educação universitária - Questionário, Ijuí, Rio Grande do Sul, Brazil (1994) (in Portuguese)

2. Brasil: Conselho Nacional de Saúde. Resolução 196/96. Diretrizes e Normas Regulamentadoras de Pesquisas Envolvendo Seres Humanos (1996) (in Portuguese), http://conselho.saude.gov.br/resolucoes/reso_96.htm (accessed January 15, 2013)

3. Brubaker, J.R., Hayes, G.R.: "We will never forget you [online]": an empirical investigation of post-mortem Myspace comments. In: Hinds, P., Tang, J.C., Wang, J., Bardram, J., Ducheneuat, N. (eds.) Proceedings of the ACM 2011 Conference on Computer Supported Cooperative Work (CSCW 2011), pp. 123-132. ACM, New York (2011), doi:10.1145/1958824

4. Carroll, E., Romano, J.: Your Digital Afterlife: When Facebook, Fickr and Twitter Are Your Estate, What's Your Legacy? New Riders Pub., Berkeley (2010)

5. Coelho, J.F.C., Falção, E.B.M.: Ensino científico e representações sociais de morte humana. In: Revista Iberoamericana de Educación, 3rd edn., vol. 39 (2006) (in Portuguese) 
6. Comitê Gestor da Internet. Brasil. Survey on the use of Information and Communication Technologies - ICT Households and Enterprises 2011.NIC.br/CETIC.br (2011),

http: / /op.ceptro.br/cgi-bin/cetic/

tic-domicilios-e-empresas-2011.pdf (accessed January 18, 2013)

7. Costa, H.: Pesquisando a escatologia da morte no imaginário católico e protestante. In: Pereira, A.P., et al. (eds.) Anais do XV Encontro Regional de História - ANPUH-Rio (2012),

http: //www. encontro2012.rj.anpuh.org/resources/anais/15/1338

400274_ARQUIVO_artigoparaseminarioanpuh.pdf

(accessed January 6, 2012)

8. Durkheim, É.: As formas elementares da vida religiosa, Martins Fontes, São Paulo, Brazil (2000) (in Portuguese)

9. Geertz, C.: A Religião como Sistema Cultural. In: A Interpretação das Culturas. LTC, Rio de Janeiro, Brazil (2008) (in Portuguese)

10. Hallam, E., Hockey, J.: Death, Memory and Material Culture. Berg Publishers, Oxford (2001)

11. IBGE: Censo Demográfico (2010) (in Portuguese),

ftp://ftp.ibge.gov.br/Censos/Censo_Demografico_2010/

Caracteristicas_Gerais_Religiao_Deficiencia/tab1_4.pdf (accessed January 6, 2012)

12. Locasto, M.E., Massimi, M., DePasquale, P.J.: Security and privacy considerations in digital death. In: Peisert, S., Ford, R., Gates, C., Herley, C. (eds.) Proceedings of the 2011 Workshop on New Security Paradigms Workshop, pp. 1-10. ACM, New York (2011), doi:10.1145/2073276.2073278

13. Maciel, C.: Issues of the social web interaction project faced with afterlife digital legacy. In: Gomes, A.S., Souza, C.S., de, S.J.A. (eds.) Proceedings of the 10th Brazilian Symposium on on Human Factors in Computing Systems and the 5th Latin American Conference on Human-Computer Interaction (IHC+CLIHC 2011), pp. 3-12. Brazilian Computer Society, Porto Alegre (2011)

14. Maciel, C., Pereira, V.C.: The influence of beliefs and death taboos in modeling the fate of digital legacy under the software developers' view. In: Workshop Memento Mori: Technology Design for the End of Life, CHI 2012, Austin, TX (May 2012), https://sites.google.com/site/chi2012eol/accepted-papers (accessed November 18, 2012)

15. Maciel, C., Pereira, V.C.: The internet generation and its representations of death: considerations for posthumous interaction projects. In: Maciel, C., Souza, P.C., de, C.J.A., Neris, V. (eds.) Proceedings of the 11th Brazilian Symposium on Human Factors in Computing Systems (IHC 2012), pp. 85-94. Brazilian Computer Society, Porto Alegre (2012)

16. Massimi, M., Odom, W., Banks, R., Kirk, D.: Matters of life and death: locating the end of life in lifespan-oriented HCI research. In: Tan, D., Fitzpatrick, G., Gutwin, C., et al. (eds.) Proceedings of CHI 2011, pp. 987-996. ACM Press, New York (2011), doi:10.1145/1978942.1979090

17. Massimi, M.: Technology and the human lifespan: learning from the bereaved. Interactions 18, 26-29 (2011)

18. Pew Research Center's Internet \& American Life Project. Photos and Videos as Social Currency (2012), http://pewinternet.org/Reports/2012/OnlinePictures . aspx (accessed January 18, 2013)

19. Rodrigues, J.C.: O Tabu da morte. Fiocruz, Rio de Janeiro (2011) (in Portuguese) 
20. Salgado, L.C., de, C., Leitão, C.F., de Souza, C.S.: A Journey Through Cultures. Springer, New York (2013)

21. Santos, C.A.F.: Os profissionais de Saúde Enfrentam - Negam a Morte. In: Martins, J., de, S. (eds.) A Morte e os Mortos na Sociedade Brasileira. Hucitec, São Paulo (1983) (in Portuguese)

22. Tapscott, D.: A hora da geração digital: como os jovens que cresceram usando a internet estão mudando tudo, das empresas aos governos. Agir Negócios, Brazil (2010) (in Portuguese)

23. Walter, T.: On Bereavement: The culture of grief. Open University Press, Philadelphia (1999)

24. Wyche, S.P., Grinter, R.E.: Extraordinary computing: religion as a lens for reconsidering the home. In: Junior, D.R.O., Arthur, R.B., Hinckley, K., et al. (eds.) Proceedings of the SIGCHI Conference on Human Factors in Computing Systems (CHI 2009), pp. 749-758. ACM, New York (2009), doi:10.1145/1518701.1518817

25. Wyche, S.P., Grinter, R.E.: Using sketching to support design research in new ways: a case study investigating design and charismatic Pentecostalism in São Paulo, Brazil. In: Mai, J.E. (ed.) Proceedings of the 2012 iConference (iConference 2012), pp. 63-71. ACM, New York (2012), doi:10.1145/2132176.2132185

26. Wyche, S.P., Hayes, G.R., Harvel, L.D., Grinter, R.E.: Technology in spiritual formation: an exploratory study of computer mediated religious communications. In: Hinds, P., Martin, D. (eds.) Proceedings of the 2006 20th Anniversary Conference on Computer Supported Cooperative Work (CSCW 2006), pp. 199-208. ACM, New York (2006), doi:10.1145/1180875.1180908

27. Zhang, M., Jennett, C., Malheiros, M., Sasse, M.A.: Data After Death: User Requirements and Design Challenges for SNSs and Email Providers. In: Workshop Memento Mori: Technology Design for the End of Life, CHI 2012 (2012), https://sites.google.com/site/chi2012eol/accepted-papers (accessed January 6, 2012) 